\title{
Comparison of the Different Techniques to Remove Fractured Endodontic Instruments from Root Canal Systems
}

\author{
Nimet Gencoglua
}

Dilek Helvacioglub

\begin{abstract}
Objectives: To evaluate the success of certain methods that can be used in the removal of separated instruments from different levels in curved and straight canals.

Methods: Instrument removal attempts were undertaken on 63 straight and 30 curved canals containing a pre-fractured instrument using the ultrasonics under the visualization of an operating microscope or conventional methods. In straight canals, a Masseran Kit was additionally used to these techniques. The success of instrument removal in relation to the techniques used and the location of the fragments in the root canal were evaluated. Successful treatment was defined by the removal or complete by passing of the fragments.

Results: The overall success rate was found $93.3 \%$ with ultrasonics and $66.6 \%$ when only conventional methods were used in curved canals. In straight canals, also the success rate was the highest with ultrasonics (95.2\%). This was followed by conventional method $(80.9 \%)$ and the least by Masserann Kit (47.6\%). When the success rate was investigated according to the location of the broken instruments, the lowest rate was found in the apical third of root canal.

Conclusions: Location of the fragment and the shape of the root canal influence the success of fractured instrument management. Ultrasonics under the visualization of an operating microscope was found to be an effective removal method. (Eur J Dent 2009;3:90-95)
\end{abstract}

Key words: Fractured instrument; Instrument removal; Operating microscope; Ultrasonics; Masserann Kit.

1. a Professor, Marmara University, Faculty of Dentistry, Department of Endodontics, Istanbul, Turkey.

b Research Assistant, Marmara University, Faculty of Dentistry, Department of Endodontics, Istanbul, Turkey.

- Corresponding author: Dilek Helvacioglu Marmara University, Faculty of Dentistry, Dept. of Endodontics,

Buyuk Ciftlik sok. No:6, Nisantasi, Istanbul, Turkey. Fax: +90 2122465247

E-mail: dhelvaciogludgmail.com

\section{INTRODUCTION}

The use of nickel-titanium rotary instruments in endodontic practice has gained popularity over the years as new instruments and techniques have been developed. NiTi rotary instruments show a high incidence of instrument fracture despite their favorable qualities. Instrument fractures during root canal treatment hinder the clinician from optimal preparation and obturation of the entire root canal system. This affects the long term 
prognosis of root canal treatment negatively. ${ }^{1,2}$

When an instrument fracture occurs during root canal preparation procedures, the clinician has to evaluate the treatment options with consideration for the pulp status, the root canal infection, the root canal anatomy, the position and type of fractured instrument and the amount of damage that would be caused to the remaining tooth structure. Removal of the fractured segment, bypassing and sealing the fragment within the root canal space or true blockage are chosen approaches. The prognosis of leaving the broken instruments versus removing them from the canal have been discussed in the literature..$^{3-5}$

At present, there is not any standardized procedure for safe and consistently successful removal. The removal of the broken fragments with traditional methods is time consuming, risky and has limited success. ${ }^{6-8}$ Today, removal of broken instruments are performed using ultrasonics, operating microscopes or microtube delivery methods. ${ }^{4-6}$

To improve the potential of safety and success of the removal procedures, special ultrasonic tips have been developed. These tips vibrate to loosen the obstruction causing minimal damage to the canal walls. 6,9 Operating dental microscopes are essential for the removal of fractured instruments. The enhanced vision with magnification and illumination from a microscope allows clinicians to observe the most coronal aspects of broken instruments and to remove them without any perforations. ${ }^{10,11}$ A technique is described that uses a staging platform combined with dry ultrasonic instrumentation around the fragment followed by the ultrasonic vibration of the fractured instrument segments in combination with an irrigating solution. All of the procedures of this technique are performed under the direct visualization and illumination of an operating microscope. 6,12,13

A Masserann Kit (Micromega, Besancon, Francel is a hollow tube device specially designed for the removal of intracanal metallic objects, such as broken files, silver points and posts. ${ }^{14}$ It has been used for over 40 years as an instrument removal device and a success rate of $73 \%$ and $44 \%$ had been reported regarding its use in anterior and posterior teeth respectively. ${ }^{15,16}$

Success of nonsurgical fractured instrument removal from root canals depends on the canal anatomy, the location of the fragment in the canal, the length of the separated fragment, the diameter and curvature of the canal itself, and the impaction of the instrument fragment into the canal wall. ${ }^{7}$ Instruments located in the straight portions of the canal can usually be removed. If separated instruments lie partially around canal curvatures and straight line access is prepared to the coronal of the fractured instrument segments, they can be removed. The removal of the broken instrument segments that are apically located to the curvature of the canal is usually not possible. ${ }^{12,17,18}$

The aim of this study was to evaluate the success rate of methods that can be used in the removal of separated instruments from different levels in curved and straight canals in vitro.

\section{MATERIALS AND METHODS}

\section{Selection and preparation of teeth}

In the present study, 63 extracted anterior teeth with single and straight roots and 30 mandibular first molars with a curvature of $>5^{\circ}$ and $\leq 20^{\circ}$ of mesial roots were used. Access cavities were prepared and the pulp tissue was removed. Working length was determined with a \#10 K file (MANI Inc., Utsunomiya, Japan) in each root canal.

\section{Instrument fractures in root canals}

Heroshaper (Micro-Mega, Besançon, France) .04 taper and size \#25 rotary instruments in curved canals and no \#25 K file (MANI Inc., Utsunomiya, Japan) in the straight canals were used as broken instruments. Instruments were notched with a knife edge bur $2.5 \mathrm{~mm}$ from the tip to facilitate file separation at a set length. Straight root canals of anterior teeth $(n=63)$ and curved canals of mandibular molars $(n=30)$ were divided into three subgroups according to the location of the fragment corresponding to apical, middle or the coronal thirds of the roots containing each 21 straight and 10 curved canals, respectively. Rotary notched instruments were run at different pressures with a high-torque handpiece to break the instruments and impact them to three different levels of the canal walls. Molar teeth were then radiographed from buccolingual direction and single rooted teeth from mesiodistal direction (Figure 1). 


\section{Removal techniques}

Broken instruments were removed either with ultrasonics or conventional method in curved canals ( $n=5$, each). However, in straight canals, the broken instruments were removed by conventional method, ultrasonics or Masserann Kit (n=7, each).

Conventional method: Access was established by Gates-Glidden drills, then $\mathrm{K}$ files were used to loosen the fractured instrument or bypassing it under the visualization of an operating microscope.

Ultrasonics: First, a straight line access created by Gates-Glidden drills then ultrasonic tips (ProUltra ENDO Tips, Dentsply Tulsa Dental, Tulsa, Oklahomal mounted on a ultrasonic handpiece (EMS, Nyon, Switzerland) were used under an operating microscope (Global Surgical, St. Louis, MO). Dry diamond coated ultrasonic tips (Types: 1-5) were used around the fragment to expose it, and then ultrasonic vibration with Nickel Titanium ultrasonic tips (Types: 6-8) were applied to remove the fragment (Figure 2).

Masserann kit: A Masserann instrument system (MicroMega, Besançon, France) was used to remove the instrument. A space around the coronal end of the fragment was created with different sizes of trephan burs. Two sizes of extractors (1.2 and $1.5 \mathrm{~mm}$ in outer diameter) were inserted into the created space to lock the exposed coronal end of the fractured segment.

Successful management of the case was defined as removal or complete bypassing the fragment without creating a perforation.

\section{RESULTS}

In terms of the definition of success, 74 of the 90 fractured instruments were removed or bypassed successfully. This resulted in a success rate of $82.2 \%$. The rate of unsuccessful attempts was $17.7 \%$. The overall success rate was found $93.3 \%$ when ultrasonic tips were used and $66.6 \%$ when only conventional methods were used in curved canals (Table 1). In straight canals, the success rate was $47.6 \%$ with the Masserann Kit, 95.2\% with ultrasonics and $80.9 \%$ with conventional method (Table 2). Conventional and ultrasonics techniques found to be more effective in removal of instruments than Masserann technique in straight canals.

When the success rate of removing instruments according to the location of canals was investigated, it was found that fragments located in the coronal one third of the root canal were removed completely in curved and straight roots in all techniques. In the middle of the canal, 16 out of $21(76.19 \%)$ instruments in straight canals and 9 out of $10(90 \%)$ in curved canals were successfully removed independently from the technique used. However in apical third of the canal, 13 out of 21 (61.90\%) instruments in straight canals and 5 out of $10(50 \%)$ in curved canals were removed.

\section{DISCUSSION}

Many factors must be considered before removal of fractured instruments is attempted. The chances of success should be balanced against potential complications. There is not any standardized procedure for the successful removal of fractured instruments. The techniques and devices used before have shown limited success. ${ }^{7}$ In the present study, Gates-Glidden bur was used to create a staging platform, followed by the ultrasonic tips to trephine around the fractured instrument as Ruddle ${ }^{6}$ described and tested by Ward et al. ${ }^{12,13}$ In their study, Ward et $\mathrm{al}^{13}$ found the ultrasonic technique successful at removing fractured rotary nickel titanium segments from narrow and curved root canals in clinical cases.

The Masserann Kit has been used for over 30 years as a device for removing intracanal broken instruments. This system is still effective in selected cases, especially those where broken instruments exist in a readily accessible position. ${ }^{16}$ On the other hand it has limited application in posterior teeth with thin and curved roots. Yoldas et $\mathrm{l}^{19}{ }^{19}$ found Masserann kit drills to increase the risk of perforations in curved canals. Friedman et $\mathrm{al}^{15}$ also considered Masseran kit to be inferior to ultrasonics.

Studies showed that to remove fractured instruments successfully depends on the type of fractured instrument, the canal anatomy, the degree of canal curvature and on the specific

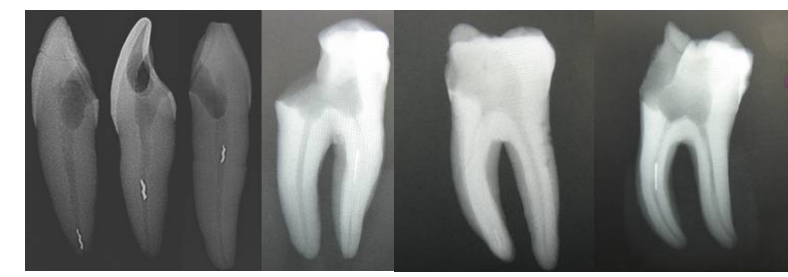

Figure 1. Radiographs showing broken instruments in different levels of curved and straight canals. 
technique used. ${ }^{5,8,18}$ Ward et al $^{12}$ indicated that it is more difficult to remove NiTi rotary instruments than hand instruments because they generally fracture at a smaller length, further apically impacted at or around the curve of narrow canal walls. Owing to their elastic memory, they tend to straighten out when they break in a curved canal.

In the present study, size \#25 .04 rotary instruments were preferred as fractured instrument at a length of $2.5 \mathrm{~mm}$ because it is the most common MAF size and fractured instrument length. ${ }^{5,7}$ Heroshaper rotary instruments were chosen in the present study as there is no study considering the removal of fractured Heroshaper instruments in the literature. Rotary systems have been introduced to deal with the complex problems of preparing curved root canals whereas conventional hand instruments have been readily

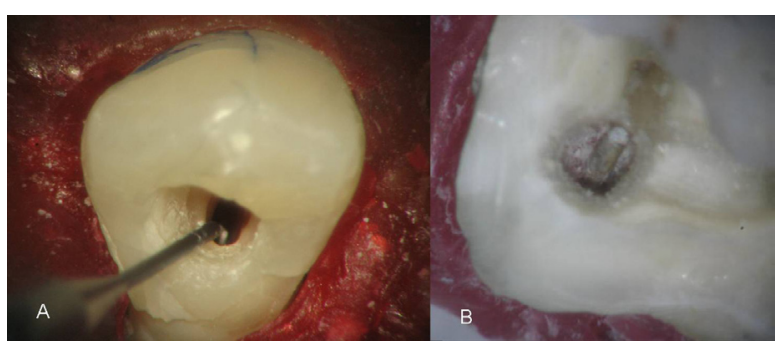

Figure 2. A- Broken instrument in the canal of single rooted tooth, B- Broken instrument in mesiolingual root canal of mandibular molar tooth. used for the preparation of straight root canals. Because of that reason, K-files were used in straight canals and Heroshaper instruments were preferred in curved canals as broken instruments. Extracted teeth were preferred rather than resin blocks because the heat generated during ultrasonic instrumentation could melt the resin blocks and the cutting efficiency of the ultrasonic tips could be reduced. Extracted teeth allow an evaluation of ultrasonic removal procedures in clinical conditions better. ${ }^{12}$ In the present study, mesiolingual curved canals were used because they are frequently involved with a fractured instrument. ${ }^{5,7}$

YaShen et $\mathrm{al}^{20}$ showed that the type of tooth affects the removal of the fragment. The effects of canal dimension and root canal irregularities on the success of removal procedure were reported by Hulsmann and Schinkel. ${ }^{7}$ In this study the success rate of removing instruments was found higher in straight and wide canals of anterior teeth than curved and narrow canals of mandibular molars.

When the success rate of broken instrument removal was investigated regarding the location of the broken instrument in the canal, 100\% success rate was obtained in coronal third of the all canals. This findings collaborated the results of Ward et

Table 1. Success rate (\%) according to the different removal methods in curved canals.

\begin{tabular}{ll|c|c|c|c|c}
\cline { 2 - 7 } & \multicolumn{3}{c}{$\begin{array}{c}\text { Curved canals } \\
\text { (ultrasonics+dental microscope) }\end{array}$} & \multicolumn{3}{c}{ Curved canals } \\
& (conventional methods+dental microscope) \\
\hline Location & $\mathrm{n}$ & Removed (n) & Success (\%) & $\mathrm{n}$ & Removed (n) & Success (\%) \\
\hline Apical $(\mathrm{n}=10)$ & 5 & 4 & $80 \%$ & 5 & 1 & $20 \%$ \\
Middle $(\mathrm{n}=10)$ & 5 & 5 & $100 \%$ & 5 & 4 & $80 \%$ \\
Coronal $(\mathrm{n}=10)$ & 5 & 5 & $100 \%$ & 5 & 5 & $100 \%$ \\
Total $(\mathrm{n}=30)$ & 15 & 14 & $93.30 \%$ & 15 & 10 & $66.60 \%$ \\
\hline
\end{tabular}

Table 2. Success rate (\%) according to the different removal methods in straight canals.

\begin{tabular}{|c|c|c|c|c|c|c|c|c|c|}
\hline \multirow[b]{2}{*}{ Location } & \multicolumn{3}{|c|}{$\begin{array}{l}\text { Straight canals } \\
\text { (Masserann) }\end{array}$} & \multicolumn{3}{|c|}{$\begin{array}{l}\text { Straight canals } \\
\text { (Ultrasonics) }\end{array}$} & \multicolumn{3}{|c|}{$\begin{array}{c}\text { Straight canals } \\
\text { (Conventional methods) }\end{array}$} \\
\hline & $\mathrm{n}$ & $\begin{array}{l}\text { Removed } \\
\text { (n) }\end{array}$ & $\begin{array}{c}\text { Success } \\
{[\%]}\end{array}$ & $\mathrm{n}$ & $\begin{array}{l}\text { Removed } \\
\text { (n) }\end{array}$ & $\begin{array}{c}\text { Success } \\
(\%)\end{array}$ & $\mathrm{n}$ & $\begin{array}{l}\text { Removed } \\
\text { (n) }\end{array}$ & $\begin{array}{c}\text { Success } \\
(\%)\end{array}$ \\
\hline Apical (n=21) & 7 & 0 & 0 & 7 & 6 & 85.7 & 7 & 4 & 57.1 \\
\hline Middle ( $n=21$ ) & 7 & 3 & 42.8 & 7 & 7 & 100 & 7 & 6 & 85.7 \\
\hline Coronal ( $n=21)$ & 7 & 7 & 100 & 7 & 7 & 100 & 7 & 7 & 100 \\
\hline Total $(n=63)$ & 21 & 10 & 47.6 & 21 & 20 & 95.2 & 21 & 17 & 80.9 \\
\hline
\end{tabular}


al's. ${ }^{12}$ However lower success rate was found by Hulsmann and Schinkel ${ }^{7}$ and Nagai et al. ${ }^{4}$ The success rate was found the lowest in the apical third. Collaborating to our findings, Souter et $\mathrm{al}^{21}$ also reported lower success rate in removing instrument from apical third of the root canal. Even visual access deeper with the microscope, it was hard to remove apically located fragments in curved canals. On the other hand, Suter et $\mathrm{al}^{5}$ found no relationship in terms of the failure rate with the location of the fractured instrument within the root canal in their study. Fors and Berg 22 suggested that objects in the apical third should be left in situ because attempts to remove can result in root perforation thus reducing the prognosis of the root canal treatment.

In the present study, removal procedure with ultrasonics had a success rate of $93.3 \%$ in curved canals and $95 \%$ in straight canals. On the other hand, using hand instrumentation with traditional methods $66.6 \%$ success rate was found in curved canals and $80 \%$ in straight canals. This study confirms that ultrasonics with the aid of an operating dental microscope is more successful in removing fractured instruments than conventional methods. Hulsmann and Schinkel ${ }^{7}$ reported a $55 \%$ $79 \%$ success rate for broken instrument removal. This rate was found to be $53 \%$ by Yashen et $a^{20}$ and $67 \%$ by Ward et al. ${ }^{12}$ In the present study, the overall success rate of the removal or bypassing of the broken instruments $(82.22 \%)$ was found higher than all previous studies reports may be due to unlimited treatment time.

\section{CONCLUSIONS}

Location of the fragment and the anatomy of the root canal influence the success of fractured instrument management. Ultrasonics under the visualization of an operating microscope is an effective removal method.

\section{ACKNOWLEDGEMENT}

This study was supported by Marmara University Scientific Research Committee ( Project no : SAGBGS-080805-0170).

\section{REFERENCES}

1. Sjögren U, Hagglund B, Sundqvist G, Wing K. Factors affecting the long-term results of endodontic treatment. $J$ Endod 1990;16:498-504.

2. Sigueira JF. Aetiology of root canal treatment failure: why well-treated teeth can fail. Int Endod J 2001;34:1-10.

3. Saunders JL, Eleazer PD, Zhang P, Michalek S. Effect of a separated instrument on bacterial penetration of obturated root canals. $J$ Endod 2004;30:177-179.

4. Nagai O, Tani N, Kayaba Y, Kodama S, Osada T. Ultrasonic removal of broken instruments in root canals. Int Endod $J$ 1986;19:298-304.

5. Suter B, Lussi A, Sequeira P. Probability of removing fractured instrument from root canals. Int Endod $J$ 2005;38:112-123.

6. Ruddle CJ. Micro-endodontic nonsurgical retreatment. Dent Clin North Am 1997;41:429-454.

7. Hulsmann M, Schinkel I. Influence of several factors on the success or failure of removal of fractured instruments from the root canal. Endod Dent Traumatol 1999;15:252-258.

8. Hulsmann M. Removal of fractured instruments using a combined automated/ultrasonic technique. $J$ Endod 1994;20:144-147.

9. Gettlemann BH, Spriggs KA, ElDeeb ME, Messer $\mathrm{HH}$. Removal of canal obstructions with the endo extractor. $J$ Endod 1991;17:608-611.

10. Suter B. A new method for retrieving silver points and separated instruments from root canals. $J$ Endod 1998;24:446-448.

11. Khayat BG. The use of magnification in endodontic therapy: the operating microscope. Pract Periodontics Aesthet Dent 1998;10:137-144.

12. Ward JR, Parashos P, Messer HH. Evaluation of an ultrasonic technique to remove fractured rotary nickeltitanium endodontic instruments from root canals: an experimental study. J Endod 2003;29:756-763.

13. Ward JR, Parashos P, Messer HH. Evaluation of an ultrasonic technique to remove fractured rotary nickeltitanium endodontic instruments from root canals: Clinical cases. J Endod 2003;29:764-767

14. Masserann J. Removal of metallic fragments from the root canal. J Br Endod Soc 1971;5:55-59.

15. Friedman S, Stabholtz A, Tamse A. Endodontic retreatment: case selection and technique. Part 3. Retreatment techniques. J Endod 1990;16:543-549.

16. Okiji T. Modified usage of the Masserann Kit for removing intracanal broken instruments. J Endod 2003;29:466-467.

17. Ruddle CJ. Nonsurgical retreatment. In: Cohen S, Burns $\mathrm{RC}$, eds. Pathways of the pulp. 8th ed. St. Louis: $C V$ Mosby Co, 2002: 875-929. 
18. Ruddle C. Nonsurgical retreatment. $J$ Endod 2004;30:827845.

19. Yoldas O, Oztunc H, Tinaz C, Alparslan N. Perforation risks associated with the use of Masserann endodontic kit drills in mandibular molars. Oral Surg Oral Med Oral Pathol Oral Radiol Endod 2004;97:513-517.

20. YaShen Peng B, Cheung GS. Factors associated with the removal of fractured instruments from root canal systems. Oral Surg Oral Med Oral Pathol Oral Radiol Endod 2004;98:605-610.

21. Souter NJ, Messer HH. Complications associated with fractured file removal using an ultrasonic technique. $J$ Endod 2005;31:450-452.

22. Fors UGH, Berg JO. Endodontic treatment of root canals obstructed by foreign objects. Int Endod $J$ 1986;19:2-10. 